\title{
МЕРЫ ГОСУДАРСТВЕННОЙ ПОДДЕРЖКИ ПРЕДПРИЯТИЙ МАЛОГО И СРЕДНЕГО БИЗНЕСА В СФЕРЕ ОНЛАЙН-ТОРГОВЛИ
}

\section{MEASURES OF GOVERNMENTAL SUPPORT FOR SMALL AND MEDIUM-SIZED BUSINESSES IN THE SPHERE OF E-COMMERCE}

\section{Popenkova}

Summary. The article is part of a series of studies devoted to the issues of state regulation of small and medium-sized enterprises in the retail sector. The article focuses on the support of enterprises engaged in online trading through marketplaces - an area that seems promising for small businesses to master. The article considers support in other countries of the world during the pandemic, provides regulatory legal acts regulating governmental support measures in Russia, a separate emphasis is placed on Moscow with the largest concentration of business in the country, and also provides an example of a collaboration of a large marketplace with a Russian export center to assist doing business in conditions of digitalization.

Keywords: governmental support for small and medium-sized enterprises, marketplaces, non-resource exporters, e-commerce, SMEs.

\section{Введение}

И меется большое число статей, посвященных вопросам государственной поддержки малых и средних предприятий (МСП). Так, Глухов и Соловьев [6] исследуют зарубежный опыт использования мер поддержки малого и среднего бизнеса в условиях распространения новой коронавирусной инфекции и меры, предпринятые Правительством Российской Федерации в условиях пандемии COVID-19. В частности, авторы рассматривают льготное кредитование, осуществляемое в рамках реализации Правил предоставления субсидий из федерального бюджета российским кредитным организациям и специализированным финансовым обществам на возмещение недополученных ими доходов по кредитам, выданным в 2019-2024 гг. субъектам МСП, а также физическим лицам, применяющим специальный налоговый режим «Налог на профессиональный доход», по льготной ставке, утвержденных Постановлением Правительства Российской Федерации от 30 декабря 2018 г. № 1764. Авторы приводят Постановление Правительства Российской Федерации от 31 марта 2020 г. № 372 «О внесении изменений в Правила предоставления субсидий из федерального бюд-
Попенкова Дарья Константиновна

К.э.н., старший преподаватель, Российский экономический университет имени Г.В. Плеханова dariakonst@yandex.ru

Аннотация. Статья является частью цикла исследований, посвященным вопросам государственного регулирования малых и средних предприятий сферы розничной торговли. В статье делается упор на поддержку предприятий, занимающихся онлайн-торговлей через маркетплейсы ту сферу, которая видится перспективной для освоения малым бизнесом. Рассматривается поддержка в других странах мира в эпоху пандемии, приводятся нормативно-правовые акты, регулирующие меры государственной поддержки в России, отдельный упор делается на Москву с наибольшей концентрацией бизнеса в стране, а также приводится пример коллаборации крупного маркетплейса с Российским экспортным центром по оказанию помощи ведения бизнеса в условиях цифровизации.

Ключевые слова: государственная поддержка малых и средних предприятий, маркетплейсы, несырьевые экспортеры, электронная торговля, МСП.

жета российским кредитным организациям и специализированным финансовым обществам на возмещение недополученных ими доходов по кредитам, выданным в 2019-2024 годах субъектам МСП, а также физическим лицам, применяющим специальный налоговый режим «Налог на профессиональный доход», по льготной ставке», в соответствии с которыми упрощены требования к заемщику, расширена возможность получения кредитов по льготной ставке для микропредприятий в сфере торговли за счет включения возможности реализации подакцизных товаров. Авторами приводится также Постановление Правительства Российской Федерации от 2 апреля 2020 г. № 410 «Об утверждении Правил предоставления в 2020 году субсидий из федерального бюджета российским кредитным организациям на обеспечение отсрочки платежа по кредитам, выданным субъектам малого и среднего предпринимательства», в соответствии с которыми предприятиям предоставляется отсрочка по начисленным процентам по кредитным договорам. Кроме того, в рамках антикризисных мер принято постановление Правительства Российской Федерации от 16 мая № 696 «Об утверждении Правил предоставления субсидий из федерального бюджета российским кредитным организациям на возмещение 
недополученных ими доходов по кредитам, выданным в 2020 г. юридическим лицам и индивидуальным предпринимателям на возобновление деятельности».

Авторы выделяют недостатки реализуемых мер, которые заключаются в следующем: включение не всех видов деятельности в перечень пострадавших отраслей, не все субъекты МСП могут претендовать на получение помощи от государства по ряду программ (например, индивидуальные предприниматели, не имеющие наемных работников); опосредованное оказание помощи МСП через кредитные организации, которым государство компенсирует ставку по ряду льготных кредитов, а это может потенциально означать отказы кредитных организаций в выдаче льготных кредитов МСП. Помимо этого, авторы указывают на то, что из бюджета Российской Федерации на помощь малому бизнесу выделили 10\% бюджета, зарезервированного на период кризисных ситуаций. При этом, например, в США, выделяется более 50\% бюджета для малого и среднего бизнеса, предназначенного на чрезвычайный случай.

\section{Постановка заАачи}

С целью изучения зарубежного опыта поддержки МСП в современных условиях обратимся к статье Симэн, Шершешева [8], которые рассматривают государственную поддержку в КНР, где МСП являются жизненно важными для экономического и социального развития, ибо именно они обеспечивают Китаю 80\% занятости в городах и 90\% новых рабочих мест, вносят существенный вклад в повышение уровня жизни населения. Согласно проведенному авторами статьи интервью с представителем китайской небольшой торговой компании Lurun, из-за введенных мер по борьбе с поставщики сырья не могут начать работу, задерживают поставки и число заказов резко сократилось, но ключевая проблема, с которой сталкивается компания,это трудности с финансированием и, несмотря на то, что Государственный совет КНР распорядился, чтобы все населенные пункты организовали системные меры для возобновления работы местных предприятий, предотвращения масштабных увольнений и стабилизации социальной занятости, компания Lurun столкнулась с рядом трудностей при возобновлении своей деятельности.

Авторы исследуют меры государственной поддержки MCП в эпоху COVID-19 на примере Пекина и провинции Чжэцзян. Так, МСП в Пекине освобождены от сбора за осмотр специального оборудования, сбора за очистку сточных вод и сбора за пользование дорогами. Если МСП продолжают работу в соответствии с государственными требованиями, без увольнений или меньшего количества увольнений, они на определен- ный период освобождаются, полностью либо частично, от арендной платы за государственную недвижимость на 2-6 месяцев. В Пекине МСП, которые испытывают трудности с налоговой декларацией из-за эпидемической ситуации, в соответствии с законодательством, могут подать заявку на отсрочку уплаты налога максимум до 3 месяцев.

Вне зависимости от COVID, в Пекине субсидируются затраты МСП на исследования и разработки. В частности, В Национальной независимой демонстрационной зоне инноваций «Чжунгуаньцунь» в соответствии с фактической ситуацией в области инвестиций в НИОКР каждому предприятию предоставляется субсидия на расходы на НИОКР в размере до 30000 долл. США. К мерам по поддержке МСП относятся также решения по снижению текущих расходов МСП, таких как расходы на электроэнергию, приостановка оплаты за коммунальные услуги, помощь в возвращении на работу сотрудников из других провинций, временная отмена платы за проезд транспортных средств по платным дорогам, помощь в стабилизации сложившихся до эпидемии традиционных цепей поставок, активная информационная поддержка.

Рассмотрев еще множество примеров поддержки, авторы приходят к выводу, что они объемны и не сводятся лишь к финансовым инструментам.

\section{Результаты}

Далее будут рассмотрены направления и нормативно-правовые акты, регулирующие государственную поддержку малому и среднему бизнесу в России (на примере города Москвы):

1 - Постановление Правительства Москвы от 18 апреля 2018 г. № 343-ПП «Об утверждении порядка предоставления субсидий из бюджета города Москвы субъектам малого и среднего предпринимательства в целях возмещения части затрат, связанных с продвижением товаров, выполняемых работ и оказываемых услуг».

В соответствии с данным Постановлением, субсидии предоставляются субъектам МСП, продвигающим товары собственного производства, выполняемые ими работы и оказываемые услуги, а также осуществляющим деятельность художественных галерей, в том числе деятельность аукционов по реализации произведений искусств. Государство компенсирует часть затрат МСП в связи с продвижением (экспонированием) товаров, работ и услуг на конгрессно-выставочных мероприятиях, международных конкурсах и фестивалях, на торговых площадках по продажам товаров, работ и услуг 
в сети Интернет, на сервисах по доставке продуктов питания, на рекламно-информационных площадках, оказывающих услуги по продвижению товаров, работ и услуг в сети Интернет [1].

2 - Приказ Правительства Москвы от 11 марта 2021 г. № П-18-12-77/21 «О проведении отбора в 2021 году получателей субсидий из бюджета города Москвы в целях государственной поддержки субъектов малого и среднего предпринимательства».

Источником финансирования расходов на выплату субсидий являются средства бюджета города Москвы, предусмотренные Департаменту предпринимательства и инновационного развития города Москвы в 202І году на реализацию подпрограммы «Москва - город для бизнеса и инвестиций Государственной программы города Москвы «Экономическое развитие и инвестиционная привлекательность города Москвы».

Согласно данному Приказу, к затратам, подлежащим возмещению, признаются затраты, связанные с участием в одном или нескольких конгрессно-выставочных мероприятиях, в одном или нескольких международных конкурсах и фестивалях, а именно:

- Регистрационный взнос, застройка и оборудование стенда, подключение к инженерным сетям выставочного комплекса, аренда выставочной площади.

- Затраты, связанные с оплатой услуг по продвижению товаров, работ и услуг на торговых площадках в сети Интернет,- комиссия торговой площадки. При этом приказом определен предельный размер компенсации: так, если вознаграждения торговых площадок превышает 20\%, размер субсидии определяется с учетом размера вознаграждения, принимаемого к расчету в размере $20 \%$ от стоимости товаров, работ, услуг субъекта МСП. Период компенсации: с 1 января 2020 по 30 ноября 2021. Компенсируются затраты на комиссию 33 маркетплейсов: Яндекс. Маркет, Беру, Wildberries, AliExpress Россия, eBay, AIZEL, Авито, OZON, Яндекс.Афиша, кассы. p $\phi$, YouDo, ZOON, PROFI.RU, Supl.biz, DressOne, STATUS: coffee, Kupivip.ru, Lamoda, Goods.ru, Legri, Детский мир, Mamsy, The Furnish, hh.ru, Bronevik. com, 101Hotels.com, Ostrovok.ru, Primepass, kassir. ru, Kinohod, Partner.ru, Yclients, Booking.com, Teodorus. art, livemaster.ru. Компенсируются затраты на комиссию сервисов доставки: Яндекс. Еда, Delivery Club [2-3].

- Затраты, связанные с оплатой услуг по продвижению товаров, работ и услуг на рекламно-информационных площадках, оказывающих услуги по продвижению товаров, работ и услуг в сети
Интернет. Предприниматели могут возместить часть затрат на продвижение товаров или услуг на рекламных интернет-площадках: Google Реклама, Яндекс. Директ, ВКонтакте, Facebook, Instagram, myTarget. Входят:

- прямые затраты на размещение контекстной рекламы в Яндекс. Директ и Google Рекламе (затраты, подтверждаемые посредством заключенных договоров с ООО «Яндекс» и ООО «Гугл»);

- прямые затраты на размещение таргетированной рекламы в социальных сетях ВКонтакте, myTarget (т.е затраты, подтверждаемые посредством заключенных договоров с ООО «В Контакте» и ООО «Мэйл.Ру»);

- затраты на размещение таргетированной рекламы в социальных сетях Facebook или Instagram, понесенные через сервисы для официальной оплаты: eLama (ООО «АДВ-сервис»), Aitarget $(000 \ll 1 »)[4]$.

В случае оказания услуг через посредника, комиссия посредника возмещению не подлежит. Представитель МСП может одновременно обратиться за компенсацией по нескольким субсидиям, включив в заявку все понесенные виды расходов на продвижение: на работу с маркетплейсами, на использование сервисов доставки еды, на рекламу в интернете, за участие в выставках и международных конкурсах. Суммарный размер компенсации в одном календарном году по всем видам расходов на продвижение останется прежним - не более 700 тыс. руб. Период компенсации: с 1 января 2020 по 30 ноября 2021.

Имеется также совместная программа субсидирования Правительства Москвы и «Яндекса», в рамках которой представители малого бизнеса оплачивают лишь $10 \%$ стоимости рекламной подписки на данном ресурсе в течение двух месяцев и получают скидку 50\% на дальнейшее полугодовое продвижение. Стоит отметить, что рекламная подписка - это простой инструмент для запуска рекламы на разных площадках Яндекса, где алгоритмы подписки автоматически создают и настраивают объявления, таргетируют рекламу в поиске Яндекса, Картах, Услугах, Дзене и на сайтах партнёров рекламной сети. Участвовать в программе могут представители малого и среднего бизнеса МоСквы:

- имеющие физическую точку продаж, например, салон красоты, кафе или автосервис;

- не продающие товары и услуги, реклама и продажа которых запрещена в РФ;

- никогда не пользовавшиеся Рекламной подпиской или Приоритетным размещением (или с последним рекламным размещением, закончившимся шесть или больше месяцев назад). 
3 - Постановление Правительства Москвы от 25 декабря 2020 г. № 2383-ПП «О внесении изменений в постановление Правительства Москвы от 17 сентября 2013 г. № 618-ПП «Об утверждении Порядка предоставления субсидий из бюджета города Москвы юридическим лицам в целях возмещения части затрат, связанных с получением обучающимися среднего профессионального образования или дополнительного профессионального образования»». Отбор производится на основании Приказа Департамента предпринимательства и инновационного развития города Москвы от 04 марта 2021 г. № П-18-12-64/21 «О проведении отбора в 2021 году» [5].

Вернуть можно до 95\% стоимости обучения, но не более 120 тысяч рублей на одного сотрудника и не более 10 млн. руб. суммарно [11]. Субсидируется получение среднего и дополнительного профессионального образования (Master of Business Administration, Executive Master of Business Administration, Master of Public Administration). Обязательные требования к заявителям:

- Наличие действующих договоров об обучении либо договоров, по которым обучение окончилось в период с 1 января 2020 года до дня подачи заявки.

- Подтвержденное обязательство обучающегося в срок не позднее 3-х месяцев после окончания обучения осуществлять непрерывную трудовую деятельность по основному месту работы у претендента, оплатившего обучение, на территории г. Москвы в течение не менее 12 календарных месяцев.

- Обеспечение размера заработной платы сотрудникам не ниже МРОТ в 2020 году в г. Москве.

- Для ИП - официально оформленные трудовые правоотношения с обучаемыми сотрудниками [18].

Для МСП Москвы, осуществляющих торговлю на Alibaba.com в настоящее время на официальном сайте Департамента предпринимательства и инновационного развития города Москвы происходит сбор заявок на получение 100\% возмещения затрат на присвоение аккаунту на Alibaba.com «Золотого» статуса, который дает несколько преимуществ: приоритет ранжирования в поисковой системе, неограниченное число товаров в витрине, профессиональная настройка инструментов для торговли, контент премиального аккаунта на 16 языках

Говоря о федеральной поддержке, а не только о той, что предусмотрена московскому бизнесу, Министерство экономического развития РФ [16] в рамках поддержи МСП в эпоху COVID-19 организовало взаи- модействие со многими сервисами, облегчающими работу торговых организаций, среди которых: CRM-система «Пачка», мессенджер для командной работы Myteam, облако для рабочих групп и почта для домена от mail.ru, ведение бухгалтерии от «СКБ-Контур», организация учета товародвижения на ресурсе «Мое дело» и др. «Мое дело» [17] позволяет малому предприятию, которое не готово вкладывать средства в покупку SAP и расширенного функционала 1C иметь не только автоматизированный сервис интернет-бухгалтерии 24/7, но и вести контроль остатков товаров и продаж, получая статистику по каждой позиции, вести поиск по ассортименту, складам, вести учёт скидок, загружая данные из Excel и накладных поставщиков. Удобен функционал и тем, что есть возможность автоматического расчет аналогов, отправки отчетности в налоговые органы, производится обмен с банками и онлайн-кассами.

В рамках нацпроекта «Малое и среднее предпринимательство» представители МСП могут получить кредит по ставке 7,75\%, если предприятие работает в приоритетных отраслях, в список которых входит розничная торговля (кредит можно получить на увеличение оборотных средств), сельское хозяйство, туризм и проч [15]. Федеральный проект «Создание условий для легкого старта и расширение доступа субъектов МСП к инфраструктуре поддержки» предусматривает улучшение условий ведения предпринимательской деятельности для малых предприятий, использующих различные системы налогообложения. МСП получат возможность оплачивать товары, работы, услуги с минимальной комиссией (не более 1\%) с использованием Системы быстрых платежей Банка России через все системно-значимые банки. Федеральный проект «Создание цифровой экосистемы, ориентированной на потребности пользователей, включающей востребованные сервисы, клиентоориентированный интерфейс» является ключевым направлением в области акселерации малого и среднего бизнеса. Цифровая экосистема обеспечит получение в режиме «одного окна» всех видов поддержки и полного спектра государственных и коммерческих услуг, с ее помощью можно будет проводить трекинг развития компаний, анализировать эффект от доведенной поддержки для адресной настройки услуг и сервисов с учетом изменений в экономической ситуации. В дальнейшем предприниматели смогут получить доступ не только к услугам и мерам поддержки, но и к коммерческим услугам, а также к онлайн-сервисам органов власти и институтов развития. Готовая платформа будет включать в себя 8 блоков: услуги и меры поддержки, государственные услуги, сервисы для бизнеса, маркетплейс, финансовые продукты, образование и переобучение, онлайн офис, защита бизнеса [14]. 
В Национальном проекте «Международная кооперация и экспорт» предусмотрена цель по обеспечению роста совокупного экспорта несырьевых неэнергетических товаров на 70\% к 2030 году в России и для ее достижения ведется работа в области создания Единого окна для несырьевых экспортеров, с помощью которого они получат онлайн-доступ к услугам, сопровождающим ведение внешнеэкономической деятельности. В соответствии с Распоряжением Правительства РФ от 16.11.2020 № 3001-р, на первом этапе у экспортеров появится возможность оформлять электронные запросы по четырем основным видам услуг - государственные сервисы, например, оформление мер господдержки, таможенных деклараций, подтверждение нулевой ставки НДС; бизнес-сервисы, аналитические сервисы и выставочная деятельность. На втором этапе планируется оказание услуг по 28 видам. До запуска сервиса экспортеры были вынуждены обращаться примерно в 20 ведомств, заполняя и получая около 70 различных форм документов и ожидая их оформления месяцами,- создание единого окна призвано упростить работу экспортеров, особенно МСП, наладив электронную коммуникацию с различными госведомствами и организациями, участвующими в предоставлении услуг в сфере экспорта. Оператором системы в сфере внешней торговли Правительством России утвержден АО «Российский экспортный центр» (РЭЦ). В целях эффективного механизма вывода продукции российских производителей на китайский рынок по каналам электронной коммерции, а также снижения рисков и затрат предпринимателей, РЭЦ открыл Национальный магазин российских пищевых товаров на внутрикитайской площадке Tmall.com [9].

Большое значение для поддержки экспорта имеют цифровые инструменты, способствующие снижению издержек и оказывающие влияние на повышение конкурентоспособности отечественных товаров на мировых рынках; актуальным остается также вопрос поддержки МСП, ориентированных на внутренний рынок в российской экономике - это не только улучшает структуру отечественной экономики, но и способствует росту и развитию экспортоориентированных предприятий. В данном направлении происходит поддержка МСП не сколько государственными органами, сколько крупным бизнесом. Так, еВау запустил международную программу «еBay Retail Revival» и совместно с органами власти разных стран оказывает консультационные услуги МСП по тому, как вести бизнес на маркетплейсах. В России предприятия в Ярославле, Новгороде и Удмуртии получают наставничество и обучение основам экспортных продаж через интернет от еВау, а также дополнительный коучинг от Российского экспортного центра и PayPal [7].

Наибольшими перспективами для экспорта обладает Ярославская область, где электронная торговая площадка еВау совместно с РЭЦ и Центром экспорта Ярославской области запустили в декабре 2018 г. проект по развитию экспорта из регионов «Город экспорта». На протяжении нескольких месяцев эксперты еВау, РЭЦ и PayPal обучали ярославских предпринимателей принципам онлайн-продаж и логистики, основам оформления требующихся документов и инструментам по продвижению продукции на электронных торговых площадках. Другим примером модно назвать проект компании еВау в сотрудничестве с Российским экспортным центром и Банком «Открытие» — «Открыты на весь мир», целью которого является поддержка предпринимателей малого и среднего бизнеса: практически весь экспортный цикл можно осуществлять, не выходя из дома в условиях пандемии.

\section{Выво $\triangle \mathrm{b}$}

Поддержка малого и среднего бизнеса в сфере торговли в России является широко обсуждаемой темой, выпускается большое число нормативно-правовых актов, декларируется много лозунгов, при этом конкретных мер адресной поддержки пока недостаточно. То, что многие страны, прошли десятилетия назад (Единое окно экспортеров, например), в России лишь запускается. Совместные проекты с крупными маркетплейсами также носят немассовый характер, а реализованы лишь для нескольких предприятий нескольких регионов страны. Для более динамичного развития бизнеса в сфере торговли товарами массового потребления в условиях цифровизации необходимо значительно более активное участие государства с привлечением крупного бизнеса. Автор статьи планирует изучить опыт других стран и в других направления поддержки и сравнить с российской практиках. Дальнейшие исследования данной темы видятся весьма любопытными.

\section{ЛИТЕРАТУРА}

1. Постановление Правительства Москвы от 18 апреля 2018 г. № 343-ПП «0б утверждении порядка предоставления субсидий из бюджета города Москвы субъектам малого и среднего предпринимательства в целях возмещения части затрат, связанных с продвижением товаров, выполняемых работ и оказываемых услуг»

2. Приказ Департамента от 6 апреля 2020 г. № П-18-12-107/20 «0б утверждении перечня и критериев соответствия торговых площадок по продажам товаров, работ и услуг, и сервисов по доставке продуктов питания в информационно-телекоммуникационной сети Интернет» 
3. Приказ Департамента предпринимательства и инновационного развития города Москвы от 23 октября 2020 г. № П-18-12-321/20 «0 внесении изменений в приказ Департамента от 6 апреля 2020 г. № П-18-12-107/20 «06 утверждении перечня и критериев соответствия торговых площадок по продажам товаров, работ и услуг, и сервисов по доставке продуктов питания в информационно-телекоммуникационной сети Интернет»»

4. Приказ Правительства Москвы от 11 марта 2021 г. № П-18-12-77/21 «0 проведении отбора в 2021 году получателей субсидий из бюджета города Москвы в целях государственной поддержки субъектов малого и среднего предпринимательства»

5. Приказ Департамента предпринимательства и инновационного развития города Москвы от 04 марта 2021 г. № П-18-12-64/21 «0 проведении отбора в 2021 году»

6. Глухов К.В., Соловьев И.А. Антикризисные решения для развития малого и среднего предпринимательства как фактор повышения экономической безопасности государства// Вестник ГуУ. 2020. № 11. С. 83-89

7. Морозенкова 0.В. Новые возможности для развития российских экспортно ориентированных предприятий малого и среднего бизнеса / 0.В. Морозенкова // Российский внешнеэкономический вестник. - 2021. — № 6. - С. 7-22.

8. Симэн Е., Шершешева М.Ю. Государственная политика КНР в отношении китайских малых и средних предприятий в условиях COVID19 // Государственное управление. Электронный вестник — 2020. — № 79. - С. 25-49

9. Единое окно «Мой экспорт» [Электронный ресурс] Режим доступа: https://myexport.exportcenter.ru/services/EHlektronnaja_torgovlja/Informacionnye_ materialy_0_dostupe_na_mezhdunarodnye_torgovye_internet_ploszadki

10. Официальный сайт Департамента предпринимательства и инновационного развития города Москвы https://mbm.mos.ru/

11. Официальный сайт Проектов Департамента предпринимательства и инновационного развития города Моckвы https://cashback.moscow.business/dpo/

12. Официальный сайт Московского инновационного кластера https://i.moscow/measure-supports/lending

13. Официальный сайт $\mathrm{A0}$ «Федеральная корпорация по развитию малого и среднего предпринимательства» (Корпорация MCП) https://corpmsp.ru

14. Федеральный проект «Создание цифровой экосистемы, ориентированной на потребности пользователей, включающей востребованные сервисы, клиентоориентированный интерфейс» https://национальныепроекты.pф/projects/msp/p-tsifrovaya-platforma-s-nbsp-mekhanizmom-adresnogopodbora-mer-podderzhki-p

15. Национальный проект «Малое и среднее предпринимательство» [Электронный ресурс] Режим доступа: https://национальныепроекты.рф/projects/ msp?utm_source=Yandex_Search\&utm_medium =CPC\&utm_campaign=56246390\&utm_term=господдержка\%206изнеса\&utm_content=msp\&ycl id $=2344637962541629182$

16. Официальный сайт Национального цифрового портала «Мой бизнес» [Электронный ресурс] Режим доступа: https://msp.economy.gov.ru/servicesremote-work

17. Официальный сайт программы «Мое дело — торговля» [Электронный ресурс] Режим доступа: https://www.moedelo.org/tovarouchet/retail-test

18. Постановление Правительства Москвы от 25 декабря 2020 г. № 2383-ПП «0 внесении изменений в постановление Правительства Москвы от 17 сентября 2013 г. № 618-ПП

(c) Попенкова Дарья Константиновна ( dariakonst@yandex.ru ).

Журнал «Современная наука: актуальные проблемы теории и практики» 